\title{
The effects of midazolam on intraocular pressure in children during examination under sedation
}

\author{
Isabel Oberacher-Velten, ${ }^{1,2}$ Christopher Prasser, ${ }^{3}$ Justine Rochon, ${ }^{4}$ Karl-Peter Ittner, ${ }^{3}$ \\ Horst Helbig, ${ }^{2}$ Birgit Lorenz ${ }^{1,5}$
}

${ }^{1}$ Department of Paediatric Ophthalmology, Strabismology, and Ophthalmologenetics, Klinikum of the University of Regensburg, Regensburg, Germany

2University Eye Hospital, Klinikum of the University of Regensburg, Regensburg, Germany

${ }^{3}$ Department of Anaesthesiology, Klinikum of the University of Regensburg, Regensburg, Germany

${ }^{4}$ Center for Clinical Studies, Klinikum of the University of Regensburg, Regensburg, Germany

${ }^{5}$ Department of Ophthalmology, Universitaetsklinikum, Giessen, Germany

\section{Correspondence to}

Dr Isabel Oberacher-Velten, University Eye Hospital, Klinikum of the University of Regensburg, Franz-Josef-Strauss-Allee 11, Regensburg 93053, Germany; isabel.velten@klinik. uni-regensburg.de

$\mathrm{IO}-\mathrm{V}$ and $\mathrm{CP}$ contributed equally to this study.

Accepted 30 April 2010

Published Online First

30 August 2010

\section{ABSTRACT}

Background To obtain reliable and accurate measurements of the intraocular pressure (IOP) in children often requires sedation or anaesthesia. Therefore, we investigated the effects of oral midazolam on IOP in children.

Methods In a prospective study, IOP was measured in 72 eyes of 36 cooperative children without glaucoma requiring general anaesthesia (mean age $3.5 \pm 1.3$ years, body weight $\leq 20 \mathrm{~kg}$ ) by using a Perkins hand-held tonometer. Measurements of IOP were performed before, and 15 and 30 min after sedation with orally administered midazolam (1 mg/kg) given as preoperative medication, and 5 and 15 min after induction of general anaesthesia. The individual IOP courses were analysed.

Results In all of the cooperative children, IOP measurement was possible after sedation with midazolam. Mean IOP was $11.2 \pm 0.3 \mathrm{mmHg}$ before sedation, $10.9 \pm 0.2 \mathrm{mmHg}$ at $15 \mathrm{~min}$, and $10.7 \pm 0.3 \mathrm{mmHg} 30 \mathrm{~min}$ after administration of midazolam. This small decrease was not statistically significant, whilst the IOP decline at 5 and 15 min after induction of general anaesthesia was statistically significant $(p<0.0001)$.

Conclusion Sedation with midazolam can be assumed to be an applicable, well-tolerated, safe method for IOP measurements in children.

\section{INTRODUCTION}

In every child with suspected or diagnosed congenital or secondary glaucoma, reliable and accurate intraocular pressure (IOP) measurements are of great clinical importance for both the diagnosis and management of glaucoma. IOP and axial length measurements are very important parameters, together with corneal size and clarity, morphology of the optic nerve and changes in refraction. Since glaucoma represents a potentially blinding condition, the significance of early diagnosis and regular follow-up examinations cannot be overemphasised. Applanatory IOP measurements in children often raise a problem for both the patient and the ophthalmologist. Very small infants may be measured during breast- or bottle-feeding, but in children a few months old and up to 2-4 years this examination is usually not possible without sedation or anaesthesia. Particularly within the first 6-12 months after glaucoma surgery, ${ }^{12}$ close periodic clinical examinations are essential, and sedation or anaesthesia are often required to obtain sufficient patient cooperation for IOP measurements.

However, anaesthetics may increase or decrease IOP to a variable degree. ${ }^{3-6}$ Thus, a method of sedation or anaesthesia would be desirable, where no relevant changes of the IOP occur, and measurements can be taken without any mental stress for the child.

In a pilot study of 14 children aged 6 months to 3 years with suspected or diagnosed congenital or secondary glaucoma (aged 6 months to 3 years), IOP could be reliably measured in every child after oral sedation with $1 \mathrm{mg} / \mathrm{kg}$ midazolam (unpublished data).

Thus, we designed a prospective study to investigate the effects of midazolam on IOP in young children after oral application of the drug and after induction of general anaesthesia.

\section{MATERIALS AND METHODS}

The study was a prospective observational clinical trial. All children's parents gave their written informed consent prior to their child's inclusion in the study. Informed consent was given to each examination and surgical procedure. The study was performed in accordance with the ethical standards of the Declaration of Helsinki.

\section{Subjects}

The following children who presented to the Department of Paediatric Ophthalmology, Strabismology and Ophthalmogenetics at the University Hospital Regensburg between August 2006 and May 2007 were recruited to participate in the study: all cooperative children aged 2-6years without glaucoma who underwent ophthalmological surgical procedures for other reasons (normal group, eg, strabismus surgery, drainage of the lacrimal duct system) with a body weight $\leq 20 \mathrm{~kg}$. Among the children younger than 2 years, four children were selected for participation because of their high cooperation during the preoperative ophthalmological examination. Applanation tonometry without sedation had been tried in 25 children aged 6 months to 2 years during their visit in our outpatient department. The children were eligible for enrolment in the study if applanation tonometry without sedation was successful, but eventually only four of the 25 children could be enrolled.

We excluded children with eye disorders that potentially influence IOP measurements (eg, anterior segment disorders) and those with contraindications against oral sedation with midazolam.

\section{Data collection}

Each child's medical and ocular history was reviewed by an anaesthesiologist and an 
ophthalmologist, and age, sex, diagnosis, current medications and surgical history were recorded.

A routine ophthalmological examination (according to the patient's age) was performed in each child prior to the inclusion into the study. Tests of visual acuity (Teller acuity cards, Cardiff cards, Lea test), orthoptic examination, slit lamp examination, funduscopy and retinoscopy were conducted.

IOP measurements were performed at the day of surgery before, and 15 and $30 \mathrm{~min}$ after the oral application of midazolam and 5 and 15 min after induction of general anaesthesia. Midazolam was administered as syrup in a concentration of $1 \mathrm{mg} / \mathrm{ml}$ in the operating room and oxygen saturation was monitored. Fifteen millilitres of midazolam syrup consisted of $15.7 \mathrm{~g}$ raspberry syrup (Caelo, Hilden, Germany) and $0.01668 \mathrm{~g}$ midazolam hydrochloride (Fagron, Barsbüttel, Germany), titrated to $\mathrm{pH} 3.2 \pm 0.1$ with $\mathrm{HCl}$ as titration solvent, solute in water for injection (aqua ad. inj.) $3.10386 \mathrm{~g}$.

General anaesthesia was induced with propofol $(3-4 \mathrm{mg} / \mathrm{kg})$ and remifentanil infusion $(0.6 \mu \mathrm{g} / \mathrm{kg} / \mathrm{min})$. Maintenance of anaesthesia was performed with remifentanil infusion $(0.15 \mu \mathrm{g} /$ $\mathrm{kg} / \mathrm{min}$ ) and sevoflurane (0.6-1.0 MAC (minimum alveolar concentration).

About $30 \mathrm{~s}$ after topical instillation of oxybuprocain (oxybuprocain- $\mathrm{HCl}, 4 \mathrm{mg} / \mathrm{ml}$ ) and fluorescein (fluorescein-sodium, $1.7 \mathrm{mg} / \mathrm{ml}$ ) into the eye, IOP was measured by one experienced ophthalmologist three consecutive times in each eye at the respective study time points using a Perkins tonometer ${ }^{7}$ (Clement Clarke International, Ltd, Harlow, UK).

Children's behaviour during IOP measurements before sedation was classified as $0=$ calm and cooperative, $1=$ mild, $2=$ moderate, $3=$ strong resistance to the examination. Sedation was estimated according to the University of Michigan Sedation Scale. $^{8}$

An IOP difference of more than $2 \mathrm{mmHg}$ was defined to be of clinical relevance, as IOP differences of 1 or $2 \mathrm{mmHg}$ are clinically negligible in most settings.

\section{Statistical analysis}

Continuous data are summarised by using means, standard deviations and ranges. The IOP at each time point for the right and the left eye are presented graphically by box plots. Linear mixed models were used to investigate the impact of eye (right, left) and time (T0-T4) on IOP. The correlation structure between the two eyes was specified as unstructured and the correlation structure over time was specified as autoregressive. Finally, age and body weight were included in the model to evaluate the potential effects of age and body weight on IOP. The significance level was set at 0.05 (two-sided). Because this was an exploratory study, no correction for multiple testing was applied. Thus, $p$ values are only descriptive in nature. Statistical analyses were carried out with SPSS version 13.0, and the linear mixed model analyses were conducted by using the procedure PROC MIXED in SAS version 9.1.

\section{RESULTS}

Thirty-six children satisfied the inclusion criteria and 72 eyes of these 36 children ( 24 boys and 12 girls; mean age $41.7 \pm 16.1$ (SD) (range 15-72) months) were analysed. The mean body weight was $15.4 \pm 3.1$ (range 10-20) kg). The mean dose of midazolam administered was $15.4 \pm 3.1 \mathrm{mg}$ ( $1 \mathrm{mg} / \mathrm{kg}$ in all patients).

The IOP values at each time point before and after sedation with midazolam as well as after induction of general anaesthesia are shown in table 1 and figure 1.

There was no difference between left and right eyes $(p=0.824)$, or interaction between eye and time $(p=0.548)$. The differences in IOP between time 0 (T0; before sedation) and time 1 and 2 (T1 and T2; 15 and $30 \mathrm{~min}$ after oral application of midazolam) were statistically the same for each eye (right eye: T1 vs T0 $p=0.193$, T2 vs T0 $p=0.088$; left eye: T1 vs T0 $p=0.219$, T2 vs T0 $p=0.130)$. Since no eye $\times$ time interaction was found, a second model without the interaction term was fitted. This second analysis revealed no eye effect $(p=0.720)$. A significant time effect was found $(p<0.001)$. However, compared with the baseline values, the IOP differences 15 and 30 min after administration of midazolam were distinctly below the clinically relevant difference of more than $2 \mathrm{mmHg}$, and they were not statistically significant (T1 vs T0 $p=0.195$; T2 vs T0 $p=0.096)$. No effects of age $(p=0.637)$ or weight $(p=0.854)$ were found.

One child regurgitated during induction of anaesthesia $30 \mathrm{~min}$ after application of $19 \mathrm{ml}$ midazolam syrup $(1 \mathrm{mg} / \mathrm{ml})$ without aspiration. No other complications related to sedation, general anaesthesia or to IOP measurement were observed.

In all patients, IOP could be measured under sedation with midazolam without remarkable resistance to the examination. Before sedation, 12 children showed slight resistance and seven showed moderate resistance. The University of Michigan Sedation Scale was 1 (minimal sedation) in 27 children and 2 (moderate sedation) in nine children 15 min after sedation with midazolam, and 1 in 26 and 2 in 10 children at 30 min. Sedation scores of 3 (deep sedation) and 4 (no reaction to extern stimuli) did not occur in this study.

\section{DISCUSSION}

In the present study, we did not find any relevant impact of midazolam on IOP when administered orally in children at a dosage of $1 \mathrm{mg} / \mathrm{kg}$. The IOP changes found amounted to 0.3-0.5 mmHg from baseline IOP under sedation with midazolam. A difference in IOP of 1 or $2 \mathrm{mmHg}$ is clinically negligible in most settings and can be assumed to be unimportant for decision-making processes. The small decrease of IOP under sedation with midazolam found in this study was not statistically significant and may be assumed to have no clinical importance.

Regarding the feasibility of IOP examinations in young children under sedation with midazolam, we were able to conduct

Table 1 Intraocular pressure (IOP) at baseline (T0), and at the four time points (15 (T1) and 30 (T2) min after oral administration of midazolam (1 mg/kg), and at 5 (T3) and 15 (T4) min after induction of general anaesthesia) in 72 eyes of 36 patients

\begin{tabular}{|c|c|c|c|c|c|}
\hline \multirow[b]{2}{*}{$\begin{array}{l}\text { Study group } \\
\text { ( } n=72 \text { eyes of } \\
36 \text { patients) }\end{array}$} & \multicolumn{5}{|c|}{ IOP $(\mathrm{mmHg})$ at baseline and at the four time points } \\
\hline & Baseline (T0) & $\begin{array}{l}15 \text { min after } \\
\text { application of } \\
\text { midazolam (T1) }\end{array}$ & $\begin{array}{l}30 \text { min after } \\
\text { application of } \\
\text { midazolam (T2) }\end{array}$ & $\begin{array}{l}5 \text { min after induction } \\
\text { of GA (T3) }\end{array}$ & $\begin{array}{l}15 \text { min after } \\
\text { induction of GA (T4) }\end{array}$ \\
\hline Right eye & $11.2 \pm 0.3$ & $10.9 \pm 0.3$ & $10.6 \pm 0.3$ & $8.1 \pm 0.3$ & $6.8 \pm 0.3$ \\
\hline Left eye & $11.2 \pm 0.3$ & $10.9 \pm 0.3$ & $10.7 \pm 0.3$ & $8.0 \pm 0.3$ & $6.7 \pm 0.3$ \\
\hline
\end{tabular}

Values are presented as mean $\pm S D$ 


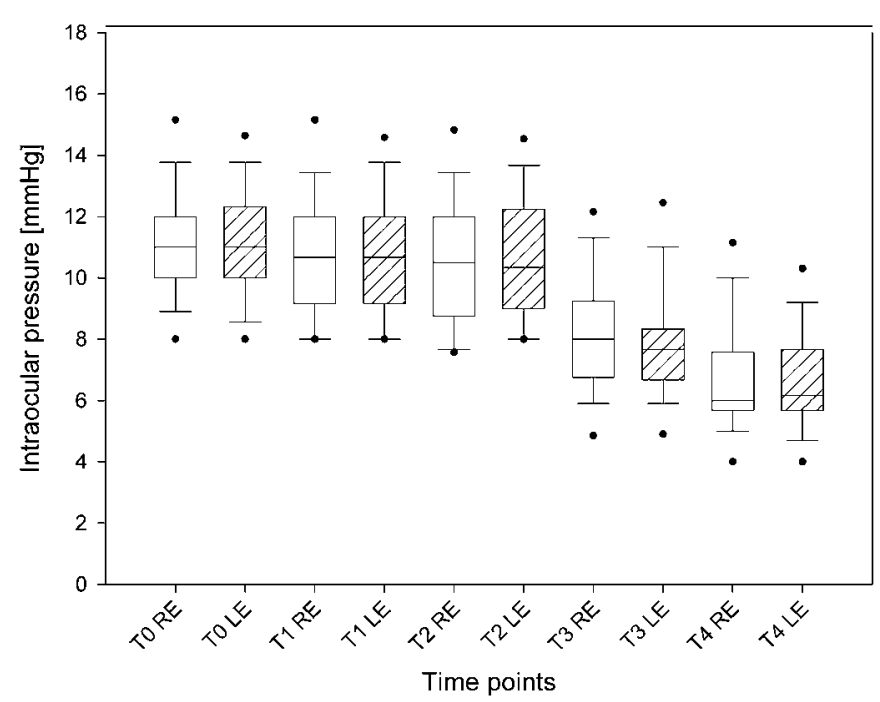

Figure 1 Box plots of intraocular pressure (IOP) values at each time point. Box plots showing mean and range of IOP $(\mathrm{mmHg})$ before (TO), and 15 (T1) and 30 (T2) min after oral administration of midazolam $(1 \mathrm{mg} / \mathrm{kg})$, and $5(\mathrm{~T} 3)$ and 15 (T4) min after induction of general anaesthesia. $L E$, left eye; $R E$, right eye.

the applanatory IOP measurements-performed in our study by using a Perkins hand-held tonometer-in all cooperative children 15 and $30 \mathrm{~min}$ after administration of midazolam without significant resistance to the examination. Children showing marked resistance to the examination or those who did not tolerate examination before sedation were not enrolled. However, even in cooperative children, IOP measurements under sedation with midazolam were significantly easier than before sedation.

Regarding the population of very young glaucoma patients (6 months to 2 years old) who attended our hospital during the last 2 years, applanation tonometry with the Perkins tonometer was possible in only five out of 35 examinations without sedation. After oral sedation with $1 \mathrm{mg} / \mathrm{kg}$ midazolam, applanation tonometry was possible in all of the remaining 30 children without marked resistance (unpublished data).

The mean age of the children in our study $(41.7 \pm 16.1$ months) was slightly above the expected mean age of children requiring sedation for IOP measurements. But to investigate the effects of midazolam on IOP, children could only be included for whom reliable and accurate IOP measurements could be taken before sedation. We did not find any statistically significant effect of the patients' age in this study group with an age range from 15 to 72 months.

The dosage of midazolam used in this study $(1 \mathrm{mg} / \mathrm{kg})$ is the highest recommended for oral administration in children up to $20 \mathrm{~kg}$. ${ }^{9}$ Above this weight, children are usually old enough to show sufficient cooperation in control examinations, which makes sedation unnecessary. To evaluate the possible impact of midazolam on IOP, the highest dose recommended was used in this study. It should be investigated whether lower doses of midazolam also lead to sufficient sedation and cooperation in IOP measurements in young children.

The study was not placebo-controlled. However, it seemed inappropriate to leave children aged between 1-6years without the anxiolytic and sedative effects of the preoperative medication.

One main problem in glaucoma diagnosis of young children is that IOP measurements often require sedation or general anaesthesia to obtain sufficient cooperation in the examination.
It is crucial to know that the IOP has not been altered falsely by anaesthetic agents. Two agents, ketamine and chloral hydrate, have mainly been used for sedation in children who require reliable and accurate IOP measurements. Ketamine, a dissociative anaesthetic, has been suggested to either elevate the $\mathrm{IOP}^{10}$ or to only have modest impact on IOP. ${ }^{6}{ }^{11-13}$ However, recovery agitation and experiences of unpleasant hallucinations have been described after sedation with ketamine alone. Since chloral hydrate is thought to have no effect on IOP, it is widely recommended for IOP measurements in children. ${ }^{14}$ The bitter flavour of the agent often necessitates rectal administration in children. Its long duration of action of up to $8 \mathrm{~h}$ and the prolonged half-life of its active metabolite trichloroethanol of $7-10 \mathrm{~h}$ reduces its controllability, particularly in an outpatient setting. Oral midazolam has been shown to be an extremely safe pre-medicant for healthy children or even children with eg, congenital heart disease. Its use in a high dosage as used in this study has been well described. ${ }^{9}$ It is an effective anxiolytic and sedative medication that is routinely used as a preoperative medication in children requiring general anaesthesia. It is a benzodiazepine with rapid onset of action 10-30 min after oral administration in children. ${ }^{15}$ Its shorter half-life time of $1-5 \mathrm{~h}$ compared with, for instance, chloral hydrate, makes its use markedly safer for children in an outpatient setting. Thus, midazolam can help to improve the compliance for close periodic control examinations in a chronic disease that carries a risk of blindness.

Gobeaux and Sardnal ${ }^{16}$ investigated the effects of intravenous midazolam on IOP in 30 adult patients. They found a decrease of mean IOP from 17.1 to $12.3 \mathrm{mmHg} 3 \mathrm{~min}$ after administration of medication. However, no control group was included. Virkkila et $a l^{17}$ and Carter et $a l^{18}$ also investigated the effects of midazolam on IOP in adult patients. Neither found a statistically significant effect of the drug on IOP in their studies.

To evaluate whether a potential effect of midazolam on IOP only becomes relevant with markedly elevated IOP values, further studies with children suffering from congenital glaucoma are needed. However, we conclude from our results that the feasibility of IOP measurements under sedation with midazolam and the insignificant impact of the drug on IOP when administered orally may be of benefit for glaucoma management in young children.

Competing interests None.

Patient consent Obtained.

Ethics approval This study was conducted with the approval of the Ethics Committee of the University Hospital Regensburg.

Provenance and peer review Not commissioned; externally peer reviewed.

\section{REFERENCES}

1. Dickens CJ, Hoskins HD. Diagnosis and treatment of congenital glaucoma. In: Ritch R, Shields MB, Krupin T, eds. The glaucomas. 2nd edn. St Louis: Mosby, 1996:739-49.

2. Jaafar MS. Care of the infantile glaucoma patient. In: Reinecke RD, ed. Ophthalmology annual. New York: Raven, 1988:15-28.

3. Hetherington J, Shaffer RN. Tonometry and tonography in congenital glaucoma. Invest Ophthalmol 1968;7:134-7.

4. Ausinsch B, Munson ES, Levy NS. Intraocular pressure in children with glaucoma during halothane anesthesia. Ann Ophthalmol 1977;9:1391-4.

5. Sator-Katzenschlager S, Deusch E, Dolezal S, et al. Sevoflurane and propofol decrease intraocular pressure equally during non-ophthalmic surgery and recovery. Br J Anaesth 2002;89:764-6.

6. Blumberg D, Congdon $\mathrm{N}$, Jampel $\mathrm{H}$, et al. The effects of sevoflurane and ketamine on intraocular pressure in children during examination under anesthesia. Am J Ophthalmol 2007;143:494-9.

7. Perkins ES. Hand-held applanation tonometer. Br J Ophthalmol 1965;49:591-3. 
8. Malviya S, Voepel-Lewis T, Tait AR, et al. Depth of sedation in children undergoing computed tomography: validity and reliability of the University of Michigan Sedation Scale (UMSS). Br J Anaesth 2002;88:241-5.

9. Coté CJ, Cohen IT, Suresh S, et al. A comparison of three doses of a commercially prepared oral midazolam syrup in children. Anesth Analg 2002;94:37-43.

10. Yoshikawa K, Murai Y. The effect of ketamine on intraocular pressure in children. Anesth Analg 1971;50:199-202.

11. Peuler M, Glass DD, Arens JF. Ketamine and intraocular pressure. Anesthesiology 1975:43:575-8

12. Ausinsch B, Rayburn RL, Munson ES, et al. Ketamine and intraocular pressure in children. Anesth Analg 1976;55:773-5.

13. Quigley HA. Childhood glaucoma results with trabeculotomy and study of reversible cupping. Ophthalmology 1982;89:219-26.
14. Fox BE, O'Brien CO, Kangas KJ, et al. Use of high dose chloral hydrate for ophthalmic exams in children: a retrospective review of 302 cases. J Pediatr Ophthalmol Strabismus 1990;27:242-4.

15. Reed MD, Rodarte A, Blumer JL, et al. The single-dose pharmacokinetics of midazolam and its primary metabolite in pediatric patients after oral and intravenous administration. J Clin Pharmacol 2001:41:1359-65.

16. Gobeaux D, Sardnal F. Midazolam and flumazenil in ophthalmology. Acta Anaesthesiol Scand Supp/ 1990;92:35-8.

17. Virkkila ME, Ali-Melkkila TM, Kanto JH. Premedication for outpatient cataract surgery: a comparative study of intramuscular alfentanil, midazolam and placebo. Acta Anaesthesiol Scand 1992;36:559-63.

18. Carter K, Faberowski LK, Sherwood MB, et al. A randomized trial of the effect of midazolam on intraocular pressure. J Glaucoma 1999;8:204-7.

\section{Cover illustration}

\section{Peacock-eyed: hundred eyes on a peacock's tail}

The word 'cockeyed' has several connotations' ${ }^{1}$ : it can apply to physical structure or to an idea or logic. Its several meanings include foolish, ridiculous, absurd, askew, crooked, intoxicated, derisory, laughable, nonsensical, preposterous, ridiculous or drunk among others. As a lay medical term, it is used to describe an individual with cross-eyes or a squint. A nursing student once wrote down a message received over the phone from a microbiology laboratory, pertaining to an eye swab, thus: 'Gram-positive cock eye grown.' She was obviously more familiar with the term 'cockeyed' than 'cocci.'

If 'cockeyed' pertains to two eyes that are not aligned, what happens when one is endowed with a hundred eyes or more, not all of which are looking the same way? The peacock, arguably nature's most beautiful bird, enjoys this status by virtue of its long tail feathers, each of which is adorned by an 'eye.' The feathers are arranged in two layers. The upper tail covers have long extensions with beautiful coloured eyes and are supported by shorter tail feathers beneath. ${ }^{2}$ The feathers are molted each year in relation to the breeding season. The shimmering crescents of blue and green are produced by the interference of light caused by concave depressions on the fine, flat hair like branches of the feathers. ${ }^{2}$

To learn where the hundred or so of the peacock's eyes came from, one has to dig into Greek mythology. ${ }^{34}$ Zeus (Jupiter) was the king of Gods, and his queen was Juno, also known as Hera. Zeus was not faithful to his wife and on one occasion pursued a beautiful mortal maiden called Io. Once, when he was with Io, he surrounded the whole region in a thick cloud to hide his actions. Juno become suspicious of the cloud and, not finding her husband around, dispelled the cloud to look for him. To cover his actions, Zeus transformed Io into a beautiful 'creamy white' heifer (cow). Juno was not fooled and took the heifer with her to her trusted minder, Argus, with instructions to guard it to the best of his ability. Argus was unique in that he could see all that was going on, as he had a hundred eyes and not all of them were asleep (shut) at any given time.

Zeus, keen to get Io back, sent his son Hermes (Mercury) to bring the heifer back at any cost. Hermes was a great storyteller and talented singer. He sought out Argus and began to tell him stories, in verse to music generated from a magic reed. The soft music gradually lulled Argus to shut one eye after another until all hundred of them were closed, and Argus was fast asleep.

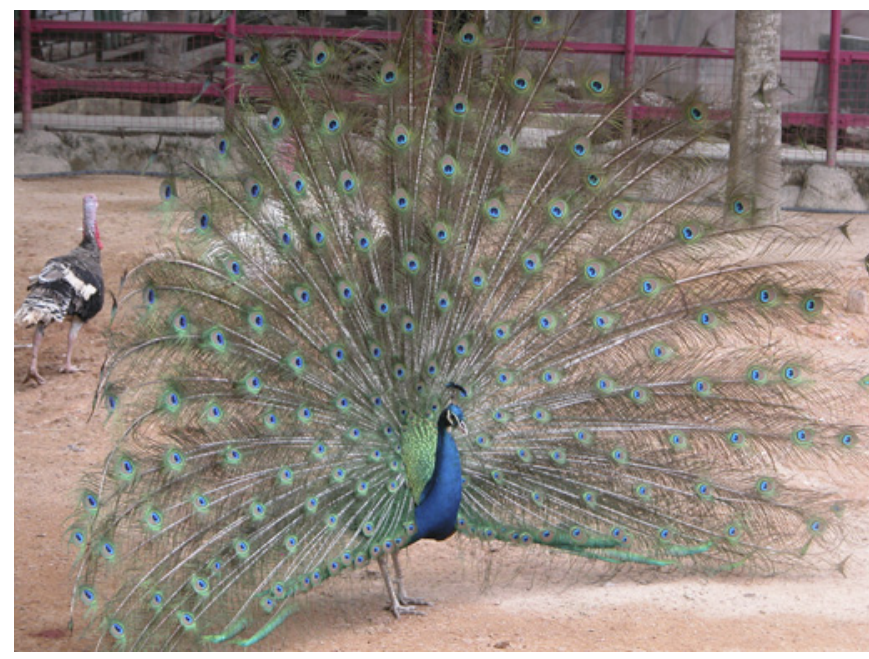

Figure 1 The 'hundred' eyes on a peacock's tail, representing the hundred eyes of Argus. Photograph by Harminder S Dua.

Thereafter, the story has two versions, each with the same end result. One version ${ }^{3}$ is that Hermes then killed Argus and took the heifer away. In this version, when Juno returns to see Argus dead, she immortalised his eyes by setting them in the tail of a peacock (cover image). The other version ${ }^{4}$ is that Hermes did not kill Argus but simply took the heifer away after Argus was fast asleep. When Juno returned, she was enraged to see Argus asleep and the heifer missing. She scoffed Argus for not being able to keep even one of his hundred eyes open and saying that her peacock was wiser as he could always tell when someone was looking at him, and she transferred Argus' hundred eyes to her peacock's tail (figure 1). Argus' name, however, has become 'a metaphor for unsleeping watchfulness.'

\section{Tasneem Khatib, Aarti Dua, Arun D Singh, Harminder S Dua}

Provenance and peer review Commissioned; internally peer reviewed.

\section{Br J Ophthalmol 2011;95:1105. doi:10.1136/bjophthalmol-2011-300631}

\section{REFERENCES}

1. http://www.thefreedictionary.com/cockeyed (accessed 19 Jun 2011). 2. http://www.tonyhill.net/peacockfeathers.ivnu (accessed 19 Jun 2011).

3. http://www.sacred-texts.com/etc/bnm/bnm27.htm (accessed 19 Jun 2011).

4. Duane D. http://www.dianeduane.com/outofambit/2011/06/07/the-eyes-in-thepeacocks-tail (accessed 19 Jun 2011). 


\section{The effects of midazolam on intraocular pressure in children during examination under sedation}

Isabel Oberacher-Velten, Christopher Prasser, Justine Rochon, Karl-Peter Ittner, Horst Helbig and Birgit Lorenz

Br J Ophthalmol 2011 95: 1102-1105 originally published online August 30, 2010

doi: 10.1136/bjo.2009.173641

Updated information and services can be found at:

http://bjo.bmj.com/content/95/8/1102

\section{These include:}

References This article cites 16 articles, 2 of which you can access for free at: http://bjo.bmj.com/content/95/8/1102\#BIBL

Email alerting Receive free email alerts when new articles cite this article. Sign up in the service box at the top right corner of the online article.

Topic Articles on similar topics can be found in the following collections Collections

\section{Notes}

To request permissions go to:

http://group.bmj.com/group/rights-licensing/permissions

To order reprints go to:

http://journals.bmj.com/cgi/reprintform

To subscribe to BMJ go to:

http://group.bmj.com/subscribe/ 